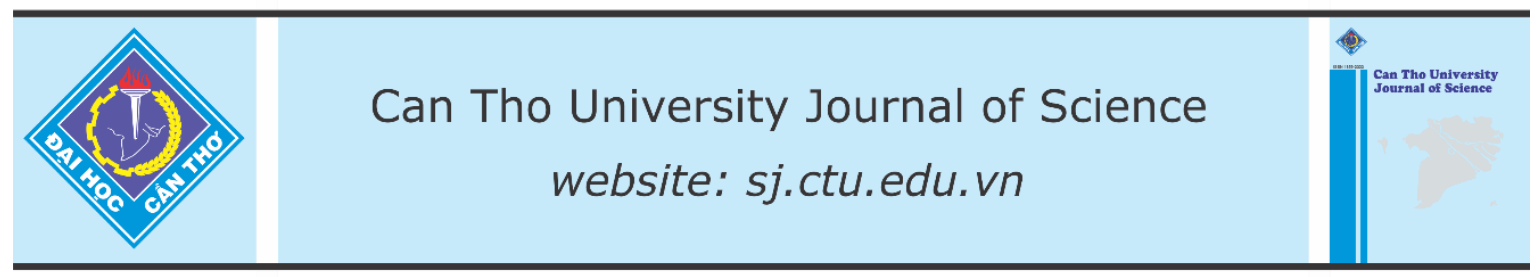

DOI: 10.22144/ctu.jen.2021.002

\title{
Establishment of a spontaneously started sourdough in Vietnam
}

\author{
Le Vu Lan Phuong", Huynh Thi Sua and Le Tri An \\ Faculty of Food Technology and Biotechnology, Can Tho University of Technology, Vietnam \\ *Correspondence: Le Vu Lan Phuong (email: lvlphuong@ctuet.edu.vn)
}

\section{Article info.}

Received 30 Oct 2019

Revised 22 Apr 2020

Accepted 31 Mar 2021

\section{Keywords}

Bread flour, Lactobacillus plantarum, Saccharomyces cerevisiae, sourdough, Wickerhamomyces anomalus

\begin{abstract}
The use of sourdoughs in bread baking in Vietnam has recently been increased but little is known about microorganisms in those sourdoughs. This study was to assess changes in $\mathrm{pH}$ value and microbial density of a sourdough from bread flour $(B F)$ and a sourdough from all-purpose flour (AF) during propagation. The results showed that the type of flour did not cause a significant difference in $\mathrm{pH}$ changes, but it could contribute to the distinct levels of lactic acid bacteria (LAB) and yeast in the two sourdoughs. The $B F$ sourdough gained proper maturation in 15 days when it reached $\mathrm{pH}$ of 3.69, $1.3 \times 10^{9} \mathrm{CFU} \mathrm{g}^{-1} \mathrm{LAB}$ and $7.4 \times 10^{8} \mathrm{CFU} \mathrm{g}^{-1}$ yeast. Meanwhile, the $A F$ sourdough had lower levels of $L A B$ and yeast $\left(3.9 \times 10^{8} \mathrm{CFU} \mathrm{g}^{-1}\right.$ and $1.0 \times 10^{8} \mathrm{CFU} \mathrm{g^{-1 }}$, respectively). Sequencing analysis revealed the presence of Lactobacillus plantarum in the BF sourdough on the $10^{\text {th }}$ and $15^{\text {th }}$ days of the propagation process. Wickerhamomyces anomalus was found on the $10^{\text {th }}$ day while Saccharomyces cerevisiae was detected on the $15^{\text {th }}$ day. This sourdough can be used in further studies to assess the benefits of sourdough in bread baking.
\end{abstract}

\section{INTRODUCTION}

The benefits of sourdough in improvement of bread texture, flavor and prolonged shelf life have long been demonstrated. Many studies have confirmed that these benefits are attributed to the presence and metabolic activities of lactic acid bacteria (LAB) and yeasts in sourdoughs (Esteve et al., 1994; Arendt et al., 2007; Coda et al., 2011; Black et al., 2013; Galle, 2013; Denkova et al., 2014).

Sourdough microbiota varies greatly depending on many factors (e.g., flour and other ingredients, environmental microbiota, dough hydration and yield, propagation steps, propagation time and temperature, and the use of starter culture or baker's yeast) (Scheirlinck et al., 2007; Minervini et al., 2012; Huys et al., 2013). It has been reported that the LAB population in most spontaneously started sourdoughs reaches an equilibrium through a three-stage process featured by the prevalence of sourdoughatypical species (e.g., Enterococcus spp. and Lactococcus lactis subsp. lactis), sourdough-typical species (e.g., species of Lactobacillus, Leuconostoc, Pediococcus, and Weissella) and highly adapted sourdough-typical species (e.g., Lb. fermentum and Lb. plantarum) (Van Der Meulen et al., 2007; Weckx et al., 2010; Huys et al., 2013). Amongst the LAB species identified in sourdoughs, obligately heterofermentative lactobacilli dominate over the others (Huys et al., 2013). Sharing the complex sourdough ecosystem with these LAB species is the yeast population. A diversity of yeast species have been identified in sourdough including those of the genera Saccharomyces, Candida and Wickerhamomyces (Meroth et al., 2003; Minervini et al., 2012; 
Huys et al., 2013). Many studies have shown that the LAB:yeast ratio usually reaches a range from 10:1 to 100:1 in mature sourdoughs (Gobbetti, 1998; Scheirlinck et al., 2007). It has also been shown that sourdough maturation is usually achieved within about 10 days (Van Der Meulen et al., 2007; Weckx et al., 2010).

Sourdough has been introduced to Vietnamese families by Western cultures in recent years but its use has yet been brought to a commercial scale. This is mainly due to the limitation of information on the microbial ecology of sourdoughs made in Vietnam.

In this study, bread flour and all-purpose flour were used to propagate two types of sourdough. The $\mathrm{pH}$ value of each type as well as LAB and yeast numbers were determined on the $5^{\text {th }}, 10^{\text {th }}$ and $15^{\text {th }}$ days of the propagation process. Sequencing analysis was used to identify the microbial species in the more prevalent sourdough.

\section{RESULTS AND DISCUSSION}

The composition of the bread flour (BF) and the allpurpose flour (AF) used in sourdough propagation is listed in Table 1 . These two types of flour are very similar except for the higher protein content in the bread flour.

Table 1. Composition (\%) of two types of flours

\begin{tabular}{lrr}
\hline Composition & $\begin{array}{r}\text { Bread flour } \\
\text { (BF) }\end{array}$ & $\begin{array}{r}\text { All-purpose } \\
\text { flour (AF) }\end{array}$ \\
\hline Protein (\%) & 14.38 & 10.62 \\
Total sugar (\%) & 3.35 & 3.42 \\
Reducing sugar (\%) & 1.78 & 1.81 \\
Total fat (\%) & $\leq 3$ & $\leq 3$ \\
\hline
\end{tabular}

For both types of sourdough, $\mathrm{pH}$ values dropped rapidly in the first five days but remained almost unchanged from the $5^{\text {th }}$ day through the $15^{\text {th }}$ day (Fig. 1). This is in accordance with previous reports on $\mathrm{pH}$ changes of most types of sourdough due to production of organic acids by sourdough LAB (Van Der Meulen et al., 2007; Corsetti, 2013; Bessmeltseva et al., 2014; Harth et al., 2018). The data also showed that $\mathrm{pH}$ was not affected by flour type. The final $\mathrm{pH}$ values of the $\mathrm{BF}$ sourdough (ca. 3.69) and the AF sourdough (ca. 3.66) were both in the range of a well-developed sourdough (Esteve et al., 1994). However, the BF sourdough had a better bread leavening capacity. This is attributable to the higher protein content in the bread flour than in the all-purpose flour (Table 1).

Lactic acid bacteria (LAB) population of the BF sourdough showed a continuous increase over the propagation period while that of the AF sourdough showed a decrease after 10 days (Fig. 2). Bacterial count of the former reached ca. $1.3 \times 10^{9} \mathrm{CFU} \mathrm{g}^{-1}$ which is a common level found in mature sourdough (Meroth et al., 2003; Scheirlinck et al., 2007; Van Der Meulen et al., 2007; Ercolini et al., 2013; Bessmeltseva et al., 2014). On the other hand, the final number of $\mathrm{LAB}$ in the latter was significantly lower $(\mathrm{p}<0.05)$, but it was in the range reported in some studies (Meroth et al., 2003; Scheirlinck et al., 2007; Van Der Meulen et al., 2007). LAB population in most sourdoughs has been reported to evolve through a three-stage process in which its number rises rapidly at first and stays constant after reaching a peak (Van Der Meulen et al., 2007; Weckx et al., 2010; Huys et al., 2013). The decrease of LAB number in the AF sourdough in this study did not show the same trend. This could be due to lower amount of nitrogen source in this type of flour (Table 1) (Scheirlinck et al., 2007; Minervini et al., 2012; Huys et al., 2013). In most of the previous studies, bread flour (high protein content) and high dough yields were used rather than all-purpose flour and low dough yields. The propagation time required for the BF sourdough in this study to reach the common number of LAB was longer than that in other reports, which could also be attributed to the properties of the flour and the low dough yield.

Meanwhile, the yeast count of the BF sourdough rose significantly from the $5^{\text {th }}$ day to the $10^{\text {th }}$ day although it remained almost the same level on the $15^{\text {th }}$ day (Fig. 3). This level reached ca. $7.4 \mathrm{x}$ $10^{8} \mathrm{CFU} \mathrm{g}^{-1}$, making the LAB-yeast ratio about 2:1. Although a ratio of 100:1 is more typical to sourdough, higher ratios of yeast were also found in some studies (Scheirlinck et al., 2007; Van Der Meulen et al., 2007). On the contrary, the yeast number of the all-purpose sourdough showed a gradual decrease over the experiment period (Fig. 3). It reached ca. $1.0 \times 10^{8} \mathrm{CFU} \mathrm{g}^{-1}$ on the $15^{\text {th }}$ day, making the LAB-yeast ratio about $4: 1$, again suggesting inadequate nitrogen source in the all-purpose flour. These differences between the two sourdoughs could explain the better bread leavening capacity of the BF sourdough although further studies are necessary. 


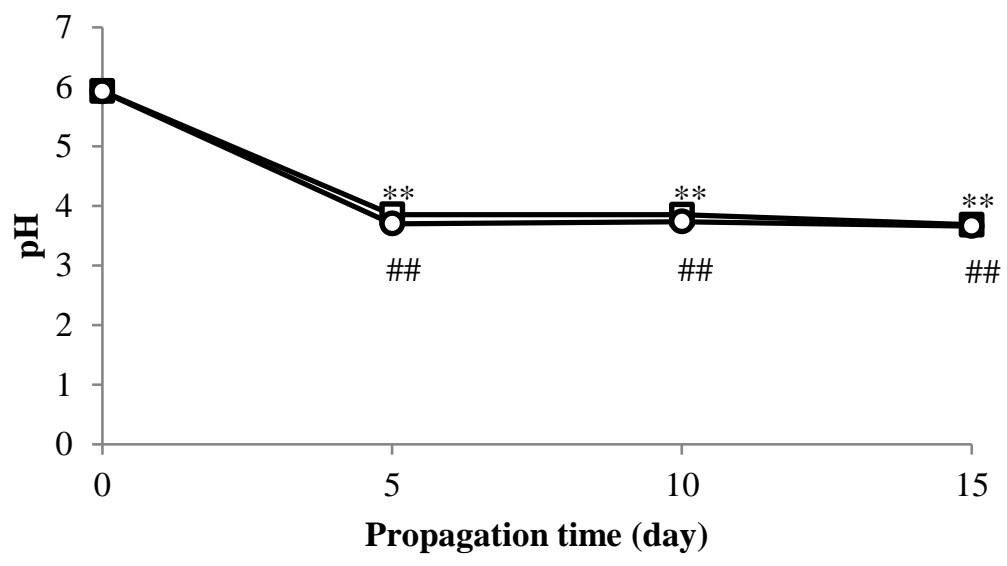

Fig. 1. pH of BF ( $\square$ ) and AF (०) sourdoughs

The data are the means of three independent experiments $\pm \mathrm{SD}(\mathrm{n}=3) .{ }^{* *} \mathrm{P}<0.01$ compared with $\mathrm{pH}$ of $\mathrm{BF}$ sourdough on the initiation day, ${ }^{\#} \mathrm{P}<0.01$ compared with $\mathrm{pH}$ of $\mathrm{AF}$ sourdough on the initiation day by LSD post-hoc test.

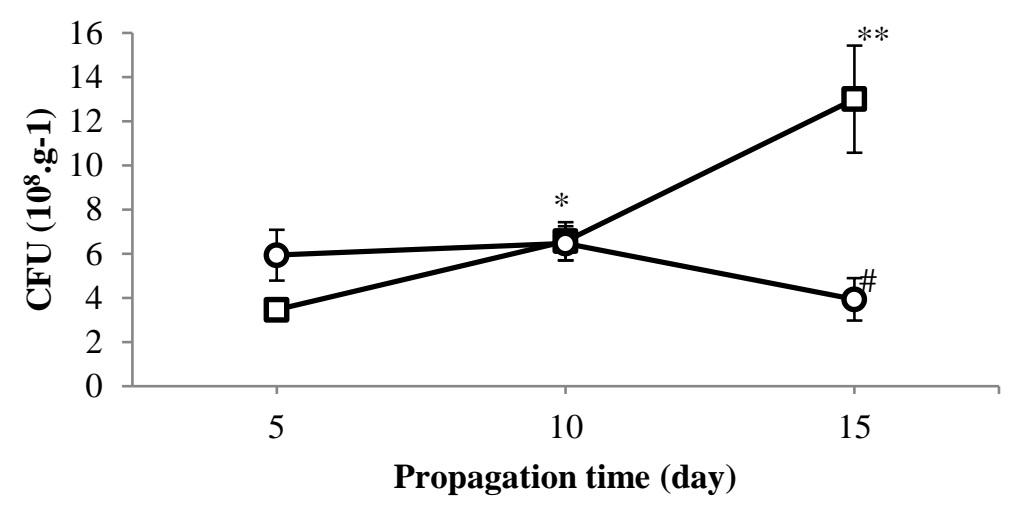

Fig. 2. Lactic acid bacteria cell numbers of BF ( $\square)$ and AF (०) sourdoughs

The data are the means of three independent experiments $\pm \mathrm{SD}(\mathrm{n}=3) .{ }^{* *} \mathrm{P}<0.01, * \mathrm{P}<0.05$ compared with $\mathrm{LAB}$ cell number of BF sourdough on the $5^{\text {th }}$ day, ${ }^{\#} \mathrm{P}<0.05$ compared with LAB cell number of AF sourdough on the $5^{\text {th }}$ day by LSD post-hoc test.

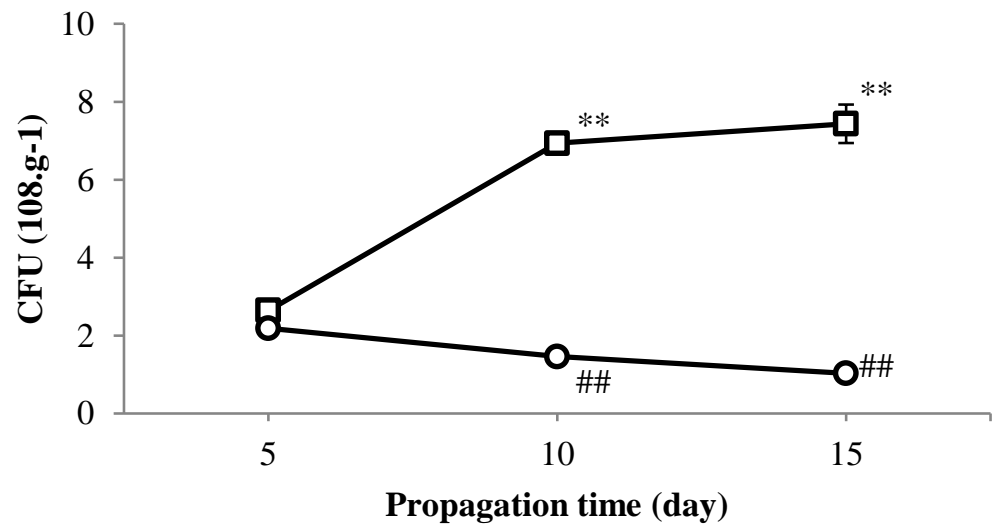

Fig. 3: Yeast cell numbers of BF ( $\square)$ and AF ( $\odot$ ) sourdoughs 
The data are the means of three independent experiments $\pm \mathrm{SD}(\mathrm{n}=3) . * * \mathrm{P}<0.01$ compared with yeast cell number of $\mathrm{BF}$ sourdough on the $5^{\text {th }}$ day, ${ }^{\#} \mathrm{P}<$ 0.01 compared with yeast cell number of AF sourdough on the $5^{\text {th }}$ day by LSD post-hoc test.

Lactic acid bacteria and yeasts in the BF sourdough on the $10^{\text {th }}$ day and the $15^{\text {th }}$ day were isolated and identified (Table 2). Lactobacillus plantarum was present in the sourdough regardless of the propagation time. According to the literature, this LAB species was commonly found in both spontaneously started sourdoughs and culture-initiated sourdoughs (Scheirlinck et al., 2007; Van Der Meulen et al.,
2007; Weckx et al., 2010; Minervini et al., 2012; Huys et al., 2013). It has also been suggested that this species is one of the highly adapted sourdoughtypical LAB species (Van Der Meulen et al., 2007; Weckx et al., 2010). Its presence could be detected in both the second stage and the third stage of the propagation process. Although the number of LAB in the BF sourdough was not as high as in other studies, the persistence of $L$. plantarum suggested that this sourdough reached maturation. As for the origin of the LAB, it has been recorded that L. plantarum adapts to sourdoughs from flour and the environment (Huys et al., 2013).

Table 2. Sequencing results

\begin{tabular}{lll}
\hline Sourdough & Closest relative & $\begin{array}{l}\text { GenBank } \\
\text { accession no. }\end{array}$ \\
\hline Bread flour, the $10^{\text {th }}$ day & $\begin{array}{l}\text { Lactobacillus plantarum strain KC28 chromosome } \\
(100 \% \text { identity) }\end{array}$ & CP026743.1 \\
\hline Bread flour, the $10^{\text {th }}$ day & $\begin{array}{l}\text { Wickerhamomyces anomalus } \\
\text { (99\% identity) }\end{array}$ & LC120363.1 \\
\hline Bread flour, the $15^{\text {th }}$ day & $\begin{array}{l}\text { Lactobacillus plantarum strain RI-113 } \\
\text { (99\% identity) }\end{array}$ & CP017406.1 \\
\hline Bread flour, the $15^{\text {th }}$ day & $\begin{array}{l}\text { Saccharomyces cerevisiae strain CEN.PK113-7D chromosome XII } \\
\text { (99\% identity) }\end{array}$ & CP022977.1 \\
\hline
\end{tabular}

Regarding yeasts, Wickerhamomyces anomalus was identified on the $10^{\text {th }}$ day, and Saccharomyces cerevisiae was identified on the $15^{\text {th }}$ day in the BF sourdough. Both of these species were found repeatedly in most types of sourdough (Meroth et al., 2003; Ercolini et al., 2013; Huys et al., 2013). The sourdough on the $15^{\text {th }}$ day showed better bread leavening capacity than it did on the $10^{\text {th }}$ day while the yeast number did not change markedly, suggesting that the type of yeast played an important role. S. cerevisiae is well known for bread leavening capacity, hence the name baker's yeast. W. anomalus, on the other hand, has not been used for bread baking except for sourdough bread. However, since we only examined one species for each time point of the propagation process, it remained to be investigated whether these species were the dominant yeasts at the respective time point. It has been suggested that both $S$. cerevisiae and $W$. anomalus in sourdoughs are from flour origin (Huys et al., 2013).

\section{ACKNOWLEDGEMENTS}

We thank An T. Nguyen and Chau T. K. Tran, Faculty of Food Technology and Biotechnology, Can Tho University of Technology, for their technical assistance.

\section{REFERENCES}

Arendt, E.K., Ryan, L.A.M. and Dal Bello, F., 2007. Impact of sourdough on the texture of bread. Food Microbiology, 24(2): 165-174.

Bessmeltseva, M., Viiard, E., Simm, J., Paalme, T. and Sarand, I., 2014. Evolution of bacterial consortia in spontaneously started rye sourdoughs during two months of daily propagation. PLoS One, 9(4): 10-11.

Black, B.A., Zannini, E., Curtis, J.M. and Gänzle, M.G., 2013. Antifungal hydroxy fatty acids produced during sourdough fermentation: Microbial and enzymatic pathways, and antifungal activity in bread. Applied and Environmental Microbiology, 79(6): 1866-1873.

Coda, R., Cassone, A., Rizzello, C.G., Nionelli, L., Cardinali, G. and Gobbetti, M., 2011. Antifungal activity of Wickerhamomyces anomalus and Lactobacillus plantarum during sourdough fermentation: Identification of novel compounds and long-term effect during storage of wheat bread. Applied and Environmental Microbiology, 77(10): 3484-3492.

Corsetti, A., 2013. Technology of Sourdough Fermentation and Sourdough Applications. In: M. Gobbetti and M. Gänzle (Eds.). Handbook on Sourdough Biotechnology. Springer. New York, pp. 85-104.

Denkova, R., Ilieva, S., Denkova, Z., Georgieva, L., Yordanova, M., Nikolova, D., \& Evstatieva, Y. 
(2014). Production of wheat bread without preservatives using sourdough starters. Biotechnology \& Biotechnological Equipment, 28(5), 889-898.

Ercolini, D., Pontonio, E., De Filippis, F., Minervini, F., La Storia, A., Gobbetti, M., \& Di Cagno, R. (2013). Microbial ecology dynamics during rye and wheat sourdough preparation. Applied and Environmental Microbiology, 79(24), 7827-7836.

Esteve, C.C., De Barber, C.B. and Martinez-Anaya, M.A., (1994). Microbial sour doughs influence acidification properties and breadmaking potential of wheat dough. Journal of Food Science, 59(3), 629-633.

Galle, S. (2013). Sourdough: A tool to improve bread structure. In Handbook on sourdough biotechnology (pp. 217-228). Springer, Boston, MA.

Gobbetti, M. (1998). The sourdough microflora: interactions of lactic acid bacteria and yeasts. Trends in Food Science \& Technology, 9(7), 267-274.

Harth, H., Van Kerrebroeck, S., \& De Vuyst, L. (2018). Impact of process conditions on the microbial community dynamics and metabolite production kinetics of teff sourdough fermentations under bakery and laboratory conditions. Food science \& nutrition, 6(6), 1438-1455.

Huys, G., Daniel, H. M., \& De Vuyst, L. (2013). Taxonomy and biodiversity of sourdough yeasts and lactic acid bacteria. In Handbook on sourdough biotechnology (pp. 105-154). Springer, Boston, MA.
Meroth, C. B., Hammes, W. P., \& Hertel, C. (2003). Identification and population dynamics of yeasts in sourdough fermentation processes by PCRdenaturing gradient gel electrophoresis. Applied and environmental microbiology, 69(12), 7453-7461.

Minervini, F., Lattanzi, A., De Angelis, M., Di Cagno, R., \& Gobbetti, M. (2012). Influence of artisan bakery-or laboratory-propagated sourdoughs on the diversity of lactic acid bacterium and yeast microbiotas. Applied and Environmental Microbiology, 78(15), 5328-5340.

Scheirlinck, I., Van der Meulen, R., Van Schoor, A., Vancanneyt, M., De Vuyst, L., Vandamme, P., \& Huys, G. (2007). Influence of geographical origin and flour type on diversity of lactic acid bacteria in traditional Belgian sourdoughs. Applied and environmental microbiology, 73(19), 6262-6269.

Van der Meulen, R., Scheirlinck, I., Van Schoor, A., Huys, G., Vancanneyt, M., Vandamme, P., \& De Vuyst, L. (2007). Population dynamics and metabolite target analysis of lactic acid bacteria during laboratory fermentations of wheat and spelt sourdoughs. Applied and Environmental Microbiology, 73(15), 4741-4750.

Weckx, S., Van der Meulen, R., Allemeersch, J., Huys, G., Vandamme, P., Van Hummelen, P., \& De Vuyst, L. (2010). Community dynamics of bacteria in sourdough fermentations as revealed by their metatranscriptome. Applied and environmental microbiology, 76(16), 5402-5408. 